\title{
Educação territorializada na favela: uma experiência de educação de jovens e adultos na favela de Manguinhos
}

Kelly Russo \& Michelle Oliveira

\begin{abstract}
Resumo:
Esse artigo discute a ressignificação do "efeito favela" nas percepções dos docentes de um curso de EJA, ao trabalharem a partir de uma proposta pedagógica centrada no conceito de "educação territorializada". Nossa pesquisa se baseia em um estudo de caso realizado em uma escola pública de Manguinhos (EJA-Manguinhos), favela situada na zona norte do município do Rio de Janeiro. Para isso, analisamos documentos, e realizamos observação e entrevistas com educadores durante o período de dois anos. Entre os resultados encontrados está a busca por uma coerência teórica-metodológica por parte dos professores, que repensam práticas e criam experiências significativas em sua relação com a comunidade local quando se sentem desafiados a pensarem em uma proposta "territorializada".
\end{abstract}

Palavras-chave:

favela; educação de jovens e adultos; território; educação popular 


\title{
Territorialized education in the favel: an experience of education of youth and adults in the favela of Manguinhos
}

\begin{abstract}
This article discusses the re-signification of the "favela effect" in the teachers' perceptions of EJA, when working on a pedagogical proposal centered on the concept of "territorialized education". Our research is based on a case study carried out in a public school in Manguinhos (EJA-Manguinhos), a favela located in the northern part of the municipality of Rio de Janeiro. We analyzed documents and we did interviews with teachers. It was possible to observe how the teachers are invited to think about a "territorialized" proposal for education in their practices.
\end{abstract}

Keywords: favela; youth and adult education; territory; popular education

\section{L'éducation territorialisée dans la favela: une expérience de l'éducation de la jeunesse et des adultes dans le favela de Manguinhos}

Résumé : Cet article traite de la redéfinition de "l'effet favela " sur les perceptions des enseignants d'un cours d'éducation d'adultes, en travaillant à partir d'une approche pédagogique centrée sur le concept de "l'éducation territorialisée. " Notre recherche est basée sur une étude de cas dans une école publique à Manguinhos (EJA-Manguinhos), située à Rio de Janeiro. Pour cela, nous analysons les documents et nous faisons des entrevues avec les enseignants au cours de la période de deux ans. Parmi les résultats, les enseignants repensent leurs pratiques à partir des expériences significatives quand ils se sentent mis au défi de penser une proposition " territorialisée ».

Mots clés : favela; éducation des jeunes et des adultes; territoire; éducation populaire

\section{La educación territorializada en la favela: una experiencia de educación de jóvenes y adultos en la favela de Manguinhos}

Resumen: Este artículo discute la resignificación del «efecto favela» en las percepciones de los docentes de un curso de EJA, al trabajar a partir de una propuesta pedagógica centrada en el concepto de «educación territorializada». Nuestra investigación se basa en un estudio de caso realizado en una escuela pública de Manguinhos (EJAManguinhos), favela situada en la zona norte del municipio de Río de Janeiro. Para ello, analizamos documentos y realizamos observación y entrevistas con los educadores del proyecto durante el período de dos años. Entre los resultados encontrados está la búsqueda de una coherencia teórico-metodológica entre los profesores, que recrían prácticas y crean experiencias significativas en su relación con la comunidad local cuando se sienten desafiados a pensar en una propuesta «territorializada».

Palabras clave: favela; educación de jóvenes y adultos; territorio; educación popular 


\section{Introdução}

Este artigo procura discutir ${ }^{1}$ a relação entre Educação de Jovens e Adultos (EJA) e favela a partir de um estudo de caso, realizado entre 2015 e 2016, no curso da EJA situado na favela de Manguinhos, no Rio de Janeiro. A EJA-Manguinhos é uma proposta de educação pública e gratuita que acontece a partir de uma parceria entre uma organização não-governamental, a Rede CCAP², e a instituição de ensino, Escola Politécnica de Saúde Joaquim Venâncio da Fundação Oswaldo Cruz (FIOCRUZ), localizada na região da Zona Norte do Rio de Janeiro.

Durante o desenvolvimento do trabalho de campo, chamou-nos a atenção o uso do conceito "educação territorializada", tanto no Plano de Curso da EJA-Manguinhos, assim como em outros documentos produzidos pela equipe pedagógica da instituição. O que é educação territorializada para esse conjunto de professores? Como os trabalhadores e trabalhadoras da EJA-Manguinhos entendem o conceito de "educação territorializada"? De alguma forma esse conceito impacta a prática pedagógica da Educação de Jovens e Adultos nessa escola?

Para discutir essas questões, realizamos uma análise de documentos produzidos pela equipe da EJA-Manguinhos no que diz respeito ao diálogo entre educação e favela (plano de curso, registro de reuniões, materiais didáticos, entre outros), e entrevistamos dois dos professores mais antigos do projeto. As entrevistas foram realizadas na própria instituição, a partir do roteiro semi-estruturado com dois professores que tiveram participação ativa na construção e no debate inicial sobre essa articulação entre os conceitos de território, escola e favela.

Esse artigo está organizado em quatro partes. Na primeira, fazemos um breve recorrido sobre o conceito de território. Na segunda, apresentamos a EJA-Manguinhos procurando discutir o contexto onde essa proposta pedagógica está inserida. $\mathrm{Na}$ terceira parte, discutirmos os conceitos de educação territorializada e efeito-favela a partir do trabalho de campo realizado na EJA-Manguinhos. Na quarta e última parte, tecemos algumas reflexões finais.

Importante ainda apresentar os marcos teóricos de nossa análise. Para discutir as concepções de jovens e adultos procuramos nos apoiar na perspectiva de sujeitos coletivos de direitos trazidos por Arroyo (2011) e contamos com Brandão (2006) e Gadotti (2011) para relacionar a educação popular com o desenvolvimento da EJA no Brasil. Em relação ao conceito de território, tivemos como base as reflexões trazidas por Milton Santos (1994) e Haesbaert (2004). Sobre o contexto da favela, contamos com as discussões de Valladares (2005) e sobre a relação educação escolar e o "efeito favela" de Burgos e Paiva (2009).

Acreditamos na importância dessa pesquisa devido a sua atualidade e a escassez de estudos sobre as relações de EJA e favela. Esperamos que nosso estudo possa 
estimular o debate sobre a aproximação da escola com as agendas de lutas dos territórios os quais estão inseridas, principalmente, no contexto de territórios favelizados e periféricos.

\section{1 - As Interfaces Conceituais: Território e territorialização}

Nesta parte do texto realizamos uma breve revisão do conceito de território a partir dos autores que nos ajudaram nessa reflexão. Importante lembrar que a nossa abordagem à relação entre educação e território não é inédita e tem antecedentes, que podem ser encontrados, por exemplo, nas experiências e reflexões sobre educação comunitária, sobre educação intercultural ou sobre práticas educativas associadas a dinâmicas de desenvolvimento local. Cada uma delas com suas especificidades e desde logo, vale também ressaltar o legado de Paulo Freire, que trabalhamos ao longo da dissertação de mestrado. Entretanto, devido a limitação do espaço, optamos por apresentar aqui apenas uma revisão pontual dos autores com os quais trabalhamos especificamente sobre o conceito de território.

A origem etimológica da palavra território está simultaneamente relacionada à terra e a terror (Haesbaert, 2004). Significa dizer que a dominação da terra representa, ao mesmo tempo, a identificação/poder/privilégio de um grupo e a perda ou restrição (terror ou medo) de outro grupo diante desta dominação. Neste sentido, território tem relação com poder, tanto no sentido de dominação (propriedade, concretude) quanto no sentido de apropriação (campo simbólico). Para entender estas duas formas de poder presentes no conceito território, nos reportaremos a diferenciação de dominação e apropriação. Para Lefebvre (1984) a dominação está vinculada a ideia de propriedade / valor de troca enquanto a apropriação carrega marcas simbólicas do vivido e sentido do uso. Segundo o autor, a apropriação deveria imperar sobre a dominação (ao se referir a dominação sob a ótica capitalista), mas o que temos assistido são as imposições capitalistas que tem enfraquecido os processos de apropriação do território engendrados pelo aparato estatal-empresarial.

É o que vivemos, por exemplo, nos processos de remoções no Rio de Janeiro, bastante intensificados nos últimos quatro anos, como podemos ver nos dados abaixo:

Tabela 1: Número de Pessoas Removidas por Gestão Municipal

\begin{tabular}{|c|c|}
\hline Governo & População removida \\
\hline Pereira Passos (1902-1906) & 20.000 \\
\hline Carlos Lacerda (1961-1965) & 30.000 \\
\hline Eduardo Paes (2009-2013) & 67.000 \\
\hline
\end{tabular}

Fonte: Gráfico estimativo com dados coletados de SMH sobre o período 2009-2013 (Rocha, 1995, p.69; Leeds, 1978, p.20 citado por Faulhaber 2015) 
O Rio de Janeiro sediou dois grandes eventos internacionais - Copa do Mundo (2014) e Olimpíadas (2016) - e dados comparativos de diferentes gestões públicas no período confirmam a intensificação das remoções. Nesse movimento da política pública podemos inferir como os interesses privados e empresariais impuseram o projeto de cidade enquanto mercadoria e, apesar de Lefebvre não se referir diretamente ao conceito de território, mas principalmente ao espaço, é possível perceber que sua perspectiva de espaço é aquela construída socialmente e não a do espaço natural, aproximando da ideia de território apresentada neste estudo.

Haesbaert (2004), em diálogo com outros autores, chama atenção para algumas características de sua perspectiva conceitual de território. Destaca que todo território vive um contínuo processo de dominação e apropriação no decorrer do tempo que se expressa por uma multiplicidade de agentes e poderes. O autor entende que o território é simultaneamente funcional e simbólico. Funcional a começar pelo território enquanto recurso ${ }^{3}$ que terá diferentes significados de acordo com a sua utilização. Poderá ter a função de "lar, abrigo e alimento" ou de "mercadoria", por exemplo. Nestas duas situações há presença simultânea da dimensão funcional e simbólica, claro que com perspectivas diferentes.

Para entender a funcionalidade (dominação) e simbologia (apropriação) do território é necessário perceber a historicidade do território e sua variação conforme o contexto histórico e geográfico. Haesbaert (2004) sintetiza três dimensões do território que podem estar inter-relacionadas, ou não, dependendo da abordagem conceitual:

1) Dimensão Política - relações de poder dentro do território que podem ser, ou não, controladas pelo Estado.

2) Dimensão Cultural - abrange a dimensão simbólica e mais subjetiva, em que o território é visto e apropriado, ou seja, valorização simbólica de um grupo em relação ao seu espaço vivido. No caso da geografia, esta utiliza muito mais outros conceitos, como paisagem ou lugar, do que território para representar a dimensão simbólica.

3) Dimensão Econômica - relação do território com a dimensão econômica. Há um forte debate sobre o uso econômico territorial (território enquanto mercadoria) e os embate entre classes sociais na relação capital-trabalho.

O "uso", principalmente na dimensão econômica e política do território, é hoje uma das principais referências na construção conceitual refletida por Milton Santos (1994). Este autor faz uma distinção interessante entre território como recurso e território como abrigo. Entende que para os atores hegemônicos o território usado é um recurso que garante seus interesses particulares, já para os atores hegemonizados o território usado é um abrigo do qual busca adaptar-se ao espaço geográfico, mas ao mesmo tempo, construindo estratégias de sobrevivência no mesmo. Faz também uma crítica a ideia de território a-histórico, reiterando a necessidade de entendê-lo historicamente mutável. 
Apesar de reconhecermos a assimetria de poder entre dominação e apropriação, apontada por Lefebvre, ainda podemos dizer que neste processo há sempre movimento de luta e resistência por um tipo de territorialidade. A territorialidade, segundo Haesbaert (2004), pode ser uma dimensão simbólica, um referencial territorial para a construção de um território, que não obrigatoriamente existe de forma concreta.

Como no conhecido exemplo da "Terra Prometida" dos judeus, territorialidade que os acompanhou e impulsionou através dos tempos, ainda que não houvesse, concretamente, uma construção territorial correspondente (HAESBAERT, 2004, p, 10). De forma semelhante, podemos citar os diferentes movimentos de favelas que são impulsionados pela "imagem/possibilidade" de uma territorialidade de direitos.

A territorialização das políticas públicas, tem sido apropriada, tanto no discurso quanto nas práticas, com diferentes significados. Ora como espaço de dominação-regulação para demarcar o poder de ação do Estado, ora como reaproximação de esferas de poder local e como possibilidade de ampliação da autonomia dos sujeitos implicados na produção dos contextos de vida do cotidiano, em um nítido movimento de resistência-apropriação (HAESBAERT, 2004). Neste sentido, as políticas e práticas da EJA estando baseada no conceito de territorialização, é afetada ao se reconhecer em um território de favela, como acontece na EJA-Manguinhos.

\section{2 - Escola na favela: contexto da EJA-Manguinhos}

A EJA-Manguinhos surge em 2004, com o nome Projeto de Educação de Jovens e Adultos de Manguinhos (PEJA Manguinhos) dentro de uma organização de base de favela, a Rede CCAP, mencionada anteriormente, a partir do acúmulo de experiências desenvolvidas na educação com jovens e adultos. Cabe contextualizar que o PEJA surge dentro de uma conjuntura de intensa violência armada, forte recorrências de enchentes, mas sobretudo, com uma forte mobilização, por parte de moradores, coletivos e instituições, em defesa da vida na favela.

Como vimos anteriormente, as representações sociais sobre um território definem perfis específicos de políticas públicas imersas nas correlações de forças de poder. Sendo assim, pensamos a política pública não como uma atividade neutra, pois, ela sempre visa interesse social, político e econômico para um grupo que não necessariamente, a classe trabalhadora. As políticas de remoções, a instalação de Unidades de Polícia Pacificadora (UPP), e outras ações nessa direção são exemplos dessa "privatização do público", algo muito bem discutido e analisado nos trabalhos de Valladares (2005), Amoroso (2012), Zaluar (1999), entre outros.

A EJA-Manguinhos, portanto, é um projeto concebido na contramão desse contexto por ser, desde sua ideia original, fruto de um envolvimento comunitário. A EJA foi construída tendo como objetivo a formação educativa dentro de uma perspectiva 
crítica e de engajamento territorial a partir de nossa pesquisa podemos identificar, desde seus primeiros documentos, a utilização da expressão "educação territorializada".

Ao analisar esses documentos iniciais, podemos constatar que o conceito de território está totalmente vinculado ao reconhecimento da favela como um território, atravessado por diferentes formas de violências e de ausência de direitos, mas também por associativismo, movimentos populares, lutas e resistências.

Interessante destacar que a grande maioria das escolas inseridas em contextos sociais de favela tendem a ser vistas como "problema", como sinaliza Burgos (2009). Em seu estudo, o autor chama atenção para dois processos de segregação urbana que são refletidos cotidianamente no espaço da escola durante o processo de ampliação de matrículas: a primeira é o esvaziamento da classe média que sai da escola pública, a partir dos meados de 1960; e segunda, o lugar simbólico que a escola passa a ocupar quando a mesma está inserida em território de favela. Nesse espaço simbólico, a escola situada na favela "marca negativamente seus alunos, professores e funcionários, e impõe conseqüências de enorme significado, tanto para o trabalho de instrução, quanto para o de socialização" (Burgos, 2009, p.8).

Sendo assim, como a EJA-Manguinhos vai se construir a partir do conceito de território, sem desconsiderar o "efeito-favela" (Burgos, 2009) entre seus profissionais e favela? Em Manguinhos, assim como outros territórios favelizados, o elo de relação entre a escola e a favela é o estudante e seus pais, mediada pelo imaginário social da cultura de violência e da culpabilização familiar e da carência extrema. Ao entendermos a escola enquanto lugar de produção e reprodução de cultura, é possível identificar manifestações da segregação urbana, como também indícios de seu papel na mitigação da mesma dentro do território da favela? Como pensar uma "educação territorializada" nesse espaço de favela?

Tanto nas entrevistas realizadas, quanto nos documentos analisados, podemos perceber o esforço de ressignificação do "efeito-favela" para se pensar no contexto da EJA-Manguinhos. Se a favela é um espaço segregado, que enfrenta a precariedade na prestação de serviços básicos, por outro lado, os documentos produzidos pela equipe pedagógica fazem muito mais referência aos espaços e estratégias de resistência comunitária.

A favela é constituída por uma grande massa populacional ${ }^{4}$ e comporta uma intensa e variada vida associativa. Para além de um contexto de violência, que não é ignorado pela equipe escolar, são reforçados nos documentos e nas reuniões pedagógicas, a visibilidade para as diversas formas de solidariedade social e coletivos organizados que constroem uma cultura de participação e reivindicação. A partir dessa ressignificação, também identificamos o esforço para o desenvolvimento de uma proposta educativa que tenha jovens e adultos de uma favela no centro desse processo, não na perspectiva da carência ou suplência, mas de ferramenta crítica para amplitude de direitos. 
Na maior parte das vezes, a descrição de jovens e adultos na modalidade de EJA é formulada somente a partir das referências ao sistema escolar: alunos que evadiram, alunos com problemas de frequência, fracasso escolar, déficit de aprendizagem, entre outros. Mas, como aponta Arroyo (2011), a trajetória de um estudante não pode se restringir à sua identidade escolar. Precisa incluir o reconhecimento de sua identidade e de sua história enquanto jovens e adultos: são homens, mulheres, pais, mães, filhos e filhas, trabalhadores e trabalhadoras, e, no caso da EJA-Manguinhos, pessoas que se constituem no enfrentamento das lutas cotidianas vivenciadas em uma favela do Rio de Janeiro.

Segundo o professor que participou da implementação do projeto, antes mesmo da expressão educação territorializada fazer parte do coletivo de professores, já havia uma preocupação, deste a concepção e implementação do projeto, em construir uma proposta pedagógica pautada nas questões culturais, políticas, sociais e econômicas de Manguinhos. Esta expertise pedagógica era fomentada pela Rede CCAP a partir da sua participação cultural e educacional no território. Antes, a palavra de ordem era "desenvolvimento local" e "educação crítica cidadã", como expressa o ex-professor e percursor do projeto:

Era entendida como educação crítica e cidadã, a partir da realidade de vida das pessoas. Onde está a realidade de vida das pessoas? Nas relações sociais colocadas neste lugar, nas relações familiares, de gênero, geracionais, nas relações de trabalho. Você tinha as questões da segurança pública... a aprendizagem que era prejudicada devido ao contexto de violência armada e militarizada. A proposta que nos dizíamos naquele momento era uma educação de jovens e adultos crítica e cidadã. Crítica e cidadã a partir das relações do lugar em que se vive e também do trabalho. Eles também viviam uma relação de trabalho subordinada e precarizada e este modelo de sociedade se faz presente neste território (P1, comunicação pessoal, 2016, p.1)

Os debates sobre território, entendendo a favela como fruto das relações de poder, foi fortalecendo cada vez mais a expressão "educação territorializada" no grupo. Não sendo, de todo modo, divergente com as bases da educação crítica e cidadã, como explica este mesmo professor entrevistado: "Quando você fala educação territorializada, você parte do pressuposto que ela é crítica e cidadã". Ao ser perguntado sobre a definição que melhor exprime as origens da proposta de educação territorializada na EJA-Manguinhos, responde:

É aquela que dialoga com a agenda de luta do território, com os conflitos do território, com as pessoas do território. É evidente que o território de Manguinhos está dentro da cidade. Então eles vão dialogar com as 
questões da cidade do Rio de Janeiro. A cidade do Rio de Janeiro está dentro do Estado. Então vai dialogar com as questões do Estado, que por sua vez está dentro do Brasil... e vai dialogar com as questões do planeta. Então é equivocado dizer que a educação territorializada só vai se restringir às questões de Manguinhos. Manguinhos é o que é, porque é fruto do desenvolvimento capitalista. Educação territorializada é uma educação atuante, militante... que não pode deixar de ser. Se ela só se restringe a sala de aula, ela deixa de ser educação territorializada (P1. Comunicação pessoal, 2016, p.3).

Segundo a fala dos dois professores entrevistados, e também a partir dos documentos analisados, a proposta de educação territorializada sempre esteve muito presente na EJA-Manguinhos: nos debates colegiados, nas construções de atividades pedagógicas e, até mesmo, na impossibilidade de ministrar aulas diante dos intensos conflitos armados, interrupções de energia elétrica ou situações de enchentes na favela. Durante o período de trabalho de campo, podemos identificar diferentes atividades pedagógicas que tentavam materializar o que se entende por "educação territorializada", como, por exemplo, a realização de atos comunitários contra a violência armada tendo a participação de estudantes e professores; a construção de uma "cartografia afetiva", onde grupos de estudantes mapeavam as potencialidades e as violações vividas; produção textual a partir de fotografias do território, criação de cordéis e poemas sobre Manguinhos envolvendo estudantes das séries iniciais do Ensino Fundamental; a festa "Pautando direitos e construindo primaveras" para arrecadação de fundos para melhoria do espaço em que estudam, entre outras atividades. Todas estas experiências parecem partir do eixo definido como estruturante do currículo ("Território, Saúde e Participação Social”) e ter tido como propósito a construção de práticas pedagógicas inovadoras e mais próximas da realidade do território, seja pelas influências de participar de outros coletivos de Manguinhos, seja pelas questões de vida trazidas pelos estudantes em sala de aula.

Uma das professoras entrevistadas acrescenta que além do próprio ambiente da favela provocar uma proposta de educação transformadora e territorializada, ou seja, um "efeito-favela" que interroga a educação e a prática docente, a própria cultura política e ideológica da organização de base mantenedora da EJA-Manguinhos nutria esta perspectiva de educação: colegiada, relacional com o território e participativa. Ao perguntar a professora sobre o que entende por educação territorializada, expressa:

É essa educação que dialoga com a vida dos estudantes, com o lugar onde estes estudantes moram. É uma educação de mão-dupla, não é só o professor que tem que estar atento, mas sim uma troca. Muitas vezes estes professores não moram no território, e aí? Você tem que ter um olhar 
e um ouvido muito mais aguçado para o que os estudantes trazem, para o que acontece nesse lugar. Você tem que procurar entender a dinâmica social desse território. Se você quer dialogar com os movimentos, você tem que conhecer estes movimentos. A educação territorializada atravessa todo mundo. Quando você vem dar aula, mesmo que você não more onde a escola está, onde os estudantes estão, mas você está ali, você circula por este lugar, a sua vida também está atravessada por este lugar (P2, comunicação pessoal, 2016, p.1)

Nesse depoimento, podemos identificar como a professora percebe a educação territorializada como sinônimo de um "diálogo com o lugar onde estes estudantes estão", ou seja, a compreensão da dinâmica social do território de moradia destes estudantes, e que a aproximação do professor com este território pode ser feito através do próprio estudante e dos movimentos sociais que ali atuam.

Perguntamos, a mesma professora, o que se esperava de um estudante que teve sua formação pautada por uma educação territorializada. Ela nos responde:

A gente espera ter plantado uma sementinha de esperança, de engajamento, de percepção do mundo que está para além das questões da própria sobrevivência. Porque é muito duro ter que levar o pão pra mesa. Muitas vezes você quer se deslocar dos problemas. Aí você vai para o futebol, para o boteco do Manoel... não quer participar... Até porque, muitas vezes, você acha que aquilo não vai dar em nada. (...) Reverter um pouco este olhar, já é alguma coisa. Plantar que a vida não é só sobrevivência; é lutar também pelos seus direitos e que isso pode dar em algum lugar, sim! (P2, comunicação pessoal, 2016, p.3).

$\mathrm{Na}$ expectativa dessa professora, a educação de jovens e adultos territorializada teria como um de seus pressupostos, o incentivo à aproximação e participação em movimentos que possam contribuir na conquista de direitos mais coletivos. Uma formação que possibilita a sua própria consciência de sujeitos de direitos e não de sujeitos que apenas "sobrevivem". Pelas entrevistas realizadas, foi possível perceber que o primeiro período de constituição da EJA-Manguinhos seus professores estavam muito mais envolvidos em construir práticas, do que sistematizá-las. Mas, aos poucos, as práticas foram exigindo reflexões, impostas pela própria práxis (ação-reflexão-ação). Paralelamente, vinha o desejo de escrever artigos como forma de compartilhamento destas experiências. Assim, o ensino foi impondo cada vez mais uma pesquisa sistematizada.

$\mathrm{Na}$ falta de recursos destinados à pesquisa, esta era realizada individualmente pelos professores, não possibilitando uma investigação mais orgânica e coletiva do grupo. Além disso, outras questões também se impunham como pesquisa: os efeitos 
da educação territorializada sobre os egressos, os impactos das violações territoriais sobre a educação (evasões, interrupções de aulas, etc). À medida que o grupo crescia, exigia-se também a clareza dos referenciais teóricos que dialogariam com a perspectiva de educação territorializada que se deseja construir na EJA-Manguinhos.

Uma experiência interessante, coletiva e participativa de sistematizar o que o grupo entendia por educação territorializada, deu-se em 2012 na construção do Plano de Curso da EJA-Manguinhos:

Daí a importância de se pensar em uma educação territorializada, em que se discutem questões ligadas ao território de moradia dos estudantes para que esta educação se constitua como um instrumento político para intervenção/transformação deste espaço. É uma educação que dialoga com outros movimentos comunitários, assim como incentiva a participação dos estudantes nestes ambientes, reconhecendo seu potencial formador, emancipador e político. É uma educação transformadora, em que os conhecimentos construídos no espaço escolar estão comprometidos com a qualidade de vida e de lutas desses educandos. (Plano de Curso, 2012, p. 5)

Esta definição incorpora como processo educativo as práticas sociais desenvolvidas nos contextos locais orientadas pelos princípios da descentralização, equidade, democracia e justiça social. É dos contextos locais que se extrai as necessidades, as resistências e os problemas relacionados às condições de vida e saúde das populações ali situadas. Neste sentido, Educação territorializada é uma forma de disputar ou fortalecer uma perspectiva de territorialidade ${ }^{5}$ dentro deste território:

Assumir uma educação territorializada implica, portanto, conhecer, refletir e dialogar com este território, no sentido de perceber seus desafios e potencialidades, bem como os "cabos de forças", poderes socioeconômicos existentes. Assim, torna-se necessário um posicionamento crítico no que diz respeito a que territorialidade queremos disputar ou reforçar neste local, isto é, a que educação queremos construir: o da perpetuação das iniqüidades ou a de um território saudável, participativo e de direitos. (Plano e Curso, 2012, p.6)

Há consciência que esta territorialidade não é de construção exclusiva do espaço escolar, mas do seu diálogo com outros coletivos e movimentos sociais que compartilham deste mesmo projeto de territorialidade. Isso pressupõe um olhar sobre a favela, para além das suas mazelas, percebendo as potencialidades, mobilizações e organicidades ali existentes. Quando perguntamos a professora sobre como concebe Manguinhos, ela nos responde: 
Manguinhos tem muita potencialidade. Ainda existe uma solidariedade muito grande entre os moradores. Se eu pudesse definir uma palavra que eu carrego, da minha infância, em relação à Manguinhos, até o dia de hoje, é a questão da solidariedade. Porque quando um está com problema, o outro vai lá e socorre. Ainda existe muito isso em Manguinhos. Agora, existem todas outras questões que marcam, não só Manguinhos, mas como todos os outros territórios de favela que é a violência. É um problema, é uma questão. A violência é algo que tem marcado negativamente, pelo menos, durante estes últimos vinte anos, muito intensamente. (...) Então, a questão de segurança pública marca muito o território, fragilizando outras políticas que, por sua vez, nunca foi lá grandes coisas por omissão do Estado nesses lugares. (...) Mas, em contra partida, você tem movimentos sociais que persistem e que não desistem da luta pela melhoria da educação, da segurança pública e da saúde. E isso nos enche de esperança. Existe fragilidades, mas também existe uma resistência, existe uma proposta de luta. Isso é algo muito positivo, em Manguinhos: existe uma mobilização (P2, comunicação pessoal: 2016, p.3).

Esta fala é extremamente importante, pois, falar de educação territorializada, ou relação escola-favela, pressupõe uma visão sobre estes territórios. São estas percepções que irão nortear o tipo de relação a ser construída entre ambos. Mas, apesar da definição de educação territorializada trazida no Plano de Curso ser uma referência para o grupo de professores, o exercício de materializar este conceito em práticas pedagógicas está sempre em debate quanto às coerências teóricas-metodológicas.

Um espaço oportuno para o debate destas questões aconteceu durante a Semana de Formação de Professores em janeiro de 2016, na qual teve como tema a "Educação Territorializada: desafios e possibilidades".

Entre as questões debatidas, a necessidade de maior clareza da delimitação territorial quando falamos de "educação territorializada" foi trazida pelos professores. Esta reflexão expressa que, se antes a EJA-Manguinhos tinha um público majoritariamente de Manguinhos, hoje apresenta estudantes da favela da Maré, do Jacaré, da Baixada Fluminense, ou seja, de outras favelas e periferias. A este respeito, podemos traçar duas análises. A primeira de que não podemos atribuir, à Manguinhos, um sentido zonal de território, mas um território que exprime as mesmas desigualdades sociais e processos de resistências como em outros territórios de favela e periferias urbana. Ou seja, falar da supressão de direitos de Manguinhos, é também falar das violações da Maré, do Alemão, ou outras, sem perder, é claro, suas especificidades. Um dos professores sugere, ao considerar as variedades de territórios dos estudantes, mas reconhecendo também sua similaridade no âmbito das desigualdades sociais, o conceito de territórios vulnerabilizados. 
Outro apontamento verificado na pesquisa é que, se por um lado, busca-se definir as especificidades de uma educação territorializada, como aquelas descritas pelos professores entrevistados, por outro, o entendimento de educação territorializada muito se aproxima, ou quase se confunde, com outras perspectivas críticas de educação, como a de educação transformadora, educação popular e educação cidadã:

Educação territorializada é transformar o estudante. Ele passa ver o território de forma diferente (Professor 1, relato durante Encontro de Formação. Docente sobre Educação Territorializada na EJA-Manguinhos, 2016) Educação territorializada é falar de assuntos críticos que ele jamais ouviria em outras escolas. É possibilitar este espaço (Professor 2, relato durante Encontro de Formação Docente sobre Educação Territorializada na EJA-Manguinhos, 2016)

Outra questão presente nos debates sobre educação territorializada refere-se a metodologia, ou seja, a coerência teórica-metodológica:

O que faço é de fato educação territorializada? [Questiona ao citar suas aulas de educação física na rua de Manguinhos com a interação das crianças que passam por ali] (Professor 3, relato durante Encontro de Formação Docente sobre Educação Territorializada na EJA-Manguinhos, 2016). Acho que abordar a história de ocupação do território de Manguinhos é uma educação territorializada (Professor 4, relato durante Encontro de Formação Docente sobre Educação Territorializada na EJA-Manguinhos, 2016)

Pensar a construção da metodologia pressupõe, necessariamente, uma questão anterior: que tipo de relação queremos construir com este território, ou seja, que "educação territorializada queremos?". A este respeito, há diferentes experiências e expectativas de relação entre a EJA-Manguinhos e o território. Uma das expectativas baseia-se no ensino crítico e territorializado, a outra emerge de relações orgânicas entre escola e movimentos sociais locais ultrapassando a dimensão da contextualização do território em sala de aula.

\section{Reflexões finais}

O estudo trouxe apontamentos importantes para as concepções e práticas pedagógicas a partir da relação educação e território a serem consideradas: a imanência e resistência de um projeto popular de educação de jovens e adultos no espaço escolar, os atravessamentos entre escola e favela, e os novos saberes e fazeres na perspectiva da educação territorializada. 
Construir uma escola pública popular é uma luta permanente da qual a participação dos movimentos sociais torna-se necessária. É nesta relação entre escola e movimentos sociais que a escola vai se retroalimentando e recriando a educação de jovens e adultos enquanto sujeitos desse processo. No contexto da EJA-Manguinhos é possível verificar, em seus documentos e práticas pedagógicas, sua busca por um diálogo constante com a favela local que parte dos conflitos e das potencialidades do território em que está inserida. Neste sentido, a educação também participa dessa política do espaço, seja reproduzindo as práticas existentes ou atuando por sua mudança. Pensar uma escola popular pressupõe, necessariamente, a sua inserção na disputa pela terra para plantar ou morar, no tiroteio nas favelas, nos alagamentos da população ribeirinha, etc.

A experiência da EJA-Manguinhos nos mostrou que novas formas de apropriação sobre o território podem produzir novas visões sobre o lugar. Uma delas é estabelecer diálogos com as potencialidades do território, como por exemplo, com os movimentos de resistências que ali são produzidos. O "efeito-favela" originalmente pensado como a imagem negativa do espaço da favela, passa a ganhar outros significados. Nesta perspectiva a educação territorializada favorece a produção de novas representações sobre a favela e da reflexão do seu papel frente a estas realidades.

O estudo verificou que apesar de haver um entendimento comum, por parte dos educadores, que educação territorializada pauta-se na relação entre educação e território, há necessidade de avançar no perfil desta relação. As práticas pedagógicas têm buscado materializar de diferentes formas: da contextualização de pautas da favela em sala de aula à construções de atividades compartilhadas com movimentos locais. A pesquisa aponta que, com o passar do tempo, mais que produzir atividades criativas e inovadoras, as práticas passam a exigir maior coerência teórica-metodológica que melhor expressem a educação territorializada pretendida na EJA-Manguinhos.

Vale ainda ressaltar que no momento de revisão deste artigo, recebemos a notícia de que a liderança comunitária da favela da Maré, Marielle Franco ${ }^{6}$, uma das vereadoras mais votadas da cidade do Rio de Janeiro, foi assassinada ${ }^{7}$. Essa triste notícia torna ainda mais importante o estudo realizado no contexto da EJA-Manguinhos, mostrando a necessidade de se conhecer e visibilizar diferentes concepções e práticas pedagógicas a partir da relação educação e território da favela. É preciso ampliar a diversidade de imagens e de realidades existentes na favela, para que sejam exigidas políticas publicas que superem as práticas violentas que tornam a população da favela sempre vítima de grupos armados: sejam aqueles ligados ao narco-trafico, sejam às milicias ou aqueles que representam o próprio Estado.

Finalizamos assim esse artigo, com uma imensa tristeza pela perda de uma militante fundamental na luta pelos direitos da favela no Rio de Janeiro, e ressaltamos a urgência e a importância de assumirmos todos, compromisso para continuar a pesquisar 
e a incentivar o desenvolvimento de praticas educativas que visem a transformação dessa sociedade violenta, injusta e desigual que insiste em ameaçar a todos que lutam por direitos humanos em nosso país.

\section{Notas}

1 "No entrelaçar de becos, lutas e a sala de aula: a experiência da EJA-Manguinhos", dissertação apresentada, como requisito parcial para obtenção do título de Mestre, ao Programa de Pós Graduação em Educação, Cultura e Comunicação em Periferias Urbanas da Universidade do Estado do Rio de Janeiro.

${ }^{2}$ A sigla CCAP designava-se até o final dos anos 90 como Centro de Cooperação e Atividades Populares. Rede CCAP é uma organização de base que atua no território de Manguinhos desde 1986, atuando, inicialmente, com a comercialização de produtos orgânicos na favela na perspectiva da segurança alimentar ampliando, posteriormente, para trabalhos voltados para Educação, Cultura e Direitos Humanos.

${ }^{3}$ A ideia de recurso entendida enquanto necessária para produção humana e não, obrigatoriamente, enquanto coisa e mercadoria podendo, também, ser esta uma das suas funcionalidades e simbologias (Raffestin, 1993:8).

${ }^{4}$ A população de Manguinhos no Rio de Janeiro é de aproximadamente 36.160 habitantes, composto por 17.284 homens e 18.876 mulheres segundo dados do Censo do IBGE de 2010.

${ }^{5}$ Coexistência de vários territórios dentro de um mesmo território, ou seja, diferentes disputas de poder dentro de uma mesma delimitação territorial (RAFFESTIN, 1993, p. 54 apud Gondim e Monken).

${ }^{6}$ Feminista e ativista do movimento negro, Marielle Franco se destacava por suas críticas a violência policial no Rio.

7 A Polícia Civil do Rio de Janeiro tenta esclarecer a morte da vereadora Marielle Franco, do Psol, e de seu motorista, Anderson Gomes, na quarta-feira 14 de marco de 2018. Sob pressão de ativistas, políticos e entidades nacionais e internacionais, os investigadores seguem sem resposta. A principal hipótese analisada pela Delegacia de Homicídios do Rio até o momento de publicação deste artigo é que se tratou de uma execução por causas politicas. Para saber mais : https:// www.cartacapital.com.br/sociedade/o-que-se-sabe-ate-agora-sobre-a-morte-de-marielle

\section{Bibliografia}

Amoroso, M. (2012). Duas faces da mesma fotografia: atraso versus progresso na cobertura fotojornalísitca de favelas do Correio da Manhã. In Mello, M. A. \& Simões , S. (org). Favelas cariocas: ontem e hoje (pp. 191-212). Rio de Janeiro: Garamond.

Arroyo, M. G. (2013). Educação de Jovens e Adultos: um campo de direitos e de responsabilidade pública. In Giovanetti, M. A. \& Gomes, N. L. (org). Diálogos na Educação de Jovens e Adultos (pp. 19-50). Belo Horizonte: Autêntica.

Brandão, C. R. (1984). Pensar a prática: escritos de viagem e estudos sobre a educação. São Paulo: Edições Loyola.

Brandão, C. R. (2006). O que é Educação Popular. São Paulo: Brasiliense.

Burgos, M. B. (2009). Escola e Projetos Sociais: uma análise do 'efeito-favela'. In Paiva, A. R. \& Burgos, M.(org). A Escola e a Favela (pp. 59-131). Rio de Janeiro: PUC-Rio, Pallas.

Ceccim, R.B. (2005). Educação Permanente em Saúde: descentralização e disseminação de capacidade pedagógica na saúde. Comunicação, Saúde e Educação. 16 (9), 161-177. 
Figueiredo, D. A. (2009). História da educação popular: uma leitura crítica. In Assumpção, R, (org). Educação popular na perspectiva freiriana (pp. 55-74). São Paulo: Editora e Livraria Instituto Paulo Freire.

Gadotti, M. \& Romão, J. E. (2011). Educação de Jovens e Adultos: teoria, prática e proposta. São Paulo: Cortez.

Ghiraldelli, P. (1991). História da Educação. São Paulo: Cortez.

Gondim, G. M., Monken, M. (2009). Territorialização em Saúde. In Pereira, I. B. \& Lima, J. C. F. (org). Dicionário da Educação Profissional em Saúde (pp. 392-399). Rio de Janeiro: EPSJV.

Haesbaert, R. (2004). Dos múltiplos territórios à multiterritorialidade. Porto Alegre: UFRGS Editora.

Kastrup, V. (2001). Aprendizagem, arte e inventção. Psicol. Estud, 6, 17-25.

Santos, M. (1994). O retorno do território. In Santos, M. (org). Território: Globalização e Fragmentação (pp.12-37). São Paulo: Hecitec e ANPUR.

Streck, D. R. (2013). Territórios de Resistência e Criatividade: Reflexões sobre os Lugares da Educação Popular. In Streck, D. R., Esteban, M. T. (org). Educação Popular: Lugar de Construção Social Coletiva (pp. 356-368). Petrópolis: Vozes.

Valladares, L. P.. A (2005). Invenção da favela: do mito de origem a favela.com. Rio de Janeiro: Editora FGV.

Zaluar, A. (1999). Violência e crime In: Miceli, S. O que ler na ciência social brasileira (1970-1995). Antropologia (pp. 13-107). São Paulo: Sumaré.

Kelly Russo

Doutora em Educação, Professora da FEBF/UERJ, Programa de Pós-

Graduação em Educação e Comunicação em Periferias Urbanas.

Email: kellyrussobr@gmail.com

Michelle Oliveira

Mestre em Educação (FEBF/UERJ), ativista pelo direito à educação na favela de Manguinhos no Rio de Janeiro.

Email: chellepedagogia@yahoo.com.br

Correspondência:

PPGCEC, Profa. Kelly Russo. FEBF-UERJ,

Rua General Manoel Rabelo, S/N.

Vila São Luís - Duque de Caxias

CEP: 25065-050

Data de Submissão: Janeiro 2018

Data de Avaliação: Abril 2018

Data de Publicação: Dezembro 2018 